\title{
Physiological Response of Juvenile Schizothorax prenanti under Supersaturated Stress
}

\author{
Quan Yuan, Kefeng Li, Ruifeng Liang†, Yuanming Wang, Jingjie Feng, Qianfeng Ji and Yaodan Zhang \\ State Key Laboratory of Hydraulics and Mountain River Engineering, Sichuan University, Chengdu 610065, China \\ $\dagger$ Corresponding author: Ruifeng Liang;
}

\section{Nat. Env. \& Poll. Tech.}

Website: www.neptjournal.com

Received: 04-01-2020

Revised: $17-02-2020$

Accepted: 16-04-2020

\section{Key Words:}

Supersaturated water

Schizothorax prenanti

Antioxidant enzyme

Net-cage experiment

Bubble disease

\begin{abstract}
Supersaturated water can adversely affect many species of fish and can sometimes lead to death. In the present study, we established an experimental platform on the downstream section of the Dagangshan Hydropower Station on the Dadu River. During flood discharge at the Dagangshan Hydropower Station, the river water supersaturation concentration at the experimental site was monitored, and a unique fish in the river section was selected for a cage experiment. Juvenile fish die under the $110 \%$ gas supersaturation conditions in the river, accompanied by symptoms of bubble disease. After the end of flood discharge, the remaining experimental fish were placed in clean water for approximately 180 days, and all the fish died. Exposing the experimental fish to a $127 \%$ concentration test tank in the laboratory revealed that the onset of death, semi-lethal time and total death time were 6.7 hours, 12 hours, 31.5 hours, respectively. The test fish that were exposed to supersaturated water for 6 hours were placed in clean water and tested every hour, and the change was minimal. Six-hour exposure may cause irreversible damage to the experimental fish.
\end{abstract}

\section{INTRODUCTION}

Supersaturated water has negative impacts on fish and widely studied for a long time. Abnormal behaviour was observed after fish were exposed to supersaturated water for short time (Gray et al. 1983, Shrimpton et al. 1990). When fish are exposed to supersaturated water for long periods, the formation of bubbles in fish tissues gradually damages the physiological functions of fish (Ebel \& Raymond 1976, Krise \& Herman 1989, Mesa et al. 2000, Mesa \& Warren 1997, Smiley et al. 2011) and may also hinder growth (Krise 1993, Liu et al. 2011). High concentrations of supersaturation may lead to acute death in fish (Backman \& Evans 2002, Ebel \& Raymond 1976, Weitkamp \& Katz 1980). Low concentrations of supersaturation lead to gas bubble disease and chronic death in fish. Specifically, some types of fish cannot avoid supersaturated water in low-saturated water (Stevens et al. 1980). Previous studies have shown that bubble disease can have irreversible negative effects on eggs, juveniles and adult fish (Backman \& Evans 2002, Jensen 1988, Smiley et al. 2011).

An important cause of supersaturation in water bodies is the supersaturation of downstream gas caused by flood discharge from dams. In the 1960s, the US Army Corps of Engineers observed supersaturated water bodies downstream of several dams along the Columbia River and its tributary, the Snake River, with total dissolved gas (TDG) saturation levels of 120-140\%; as a result, $18.1 \%$ of the fish downstream of the dam suffered from air bubble disease (Nakasone 1987). Colt et al. (1991) found that water oversaturation downstream of the Folsom Dam in the United States was 126-130\%. To test the effects of supersaturation on downstream fish during dam flood discharge, a series of field surveys were conducted. A large number of fish with bubble disease were found in Lake Wisconsin (Ryan \& Dawley 1998). During flood discharge, a large number of wild fishes with bubble disease were detected in an ice port reservoir and the area downstream of the ice port and Bonneville Dam (Bouck 1980).

In recent years, a large number of water conservancy projects have been built in China. During flood discharge from the water conservancy projects, the total dissolved gas supersaturated concentration ranges from $120 \%$ to $143 \%$. Rivers that are hundreds of kilometres downstream of the Manwan and Dachaoshan Dams are supersaturated $(\mathrm{Qu}$ et al. 2011). Such supersaturated concentrations lead to a higher risk of bubble disease in downstream river fish, but studies on the effects of supersaturation on the endemic fish in these rivers are still lacking (Cao et al. 2016, Huang et al. 2010, Yuan et al. 2018). Juveniles are more sensitive to supersaturation than adult fish, which is particularly worthy of attention (Weitkamp \& Katz 1980). 
The extent of the effects of supersaturation on fish depends on the concentration and time. The degree of the negative impact of supersaturation on fish can be determined by their physiological response before the lethal time is reached. On the one hand, TDG saturation can be regarded as a kind of water pollutant. Fish tissue enzyme activity is sensitive to environmental toxic reactions (Livingstone 2001). On the other hand, blood is a relatively stable indicator. Fish blood indicators are widely used to evaluate the health status of fish and their adaptation to the environment. Fish blood is an important physiological, pathological and toxicological indicator. The organic components of blood in fish also change when fish are sick (Bálint et al. 1997, Ceron et al. 1996). The functional changes in organisms that are indicated by changes in blood indexes provide a powerful basis for elucidating the mechanism of environmentally toxic substances.

This study aimed to assess the damage caused by flood discharge at the Dagangshan Dam to the endangered rivers. During flood discharge at the dam, we selected juvenile Prenant's schizothoracin (Schizothorax prenanti) as the research subjects to carry out a cage experiment in the downstream channel and assess the death characteristics and presence of bubble disease. The fish that survived the flood were then placed in clear water. Observations were subsequently made for half a year. We then analysed the death characteristics of the experimental fish in supersaturated water in the laboratory. At the same time, the physiological responses of the experimental fish to supersaturated water before the lethal time in supersaturation and the physiological changes in the experimental fish suffering from bubble disease after saturation stress during recovery in clear water were studied. The results of this study can serve as a reference for protecting this species.

\section{MATERIALS AND METHODS}

\section{Ethics Statement}

The experimental proposal was approved by the Ethics Committee for Animal Experiments of the College of Life Sciences of Sichuan University. All experiments were exe- cuted in accordance with the animal management regulations of Sichuan Province in China.

\section{Experiment Fish}

This study was conducted using six-month-old juvenile Prenant's schizothoracin that were obtained from the Sichuan Fisheries Research Institute. Healthy and active individuals were selected. Two days before the start of the field experiment, the experimental fish were transported to the experimental site for temporary maintenance (Fig. 1) to eliminate the stress response of the experimental fish during transportation. A plastic water tank (length: $0.4 \mathrm{~m}$; width: $0.3 \mathrm{~m}$; and height: $0.3 \mathrm{~m}$ ) was filled with water and used for temporarily raising the larvae. The clear water in the holding tank was taken from the Dagangshan Reservoir, and the water temperature was close to the water temperature of the river where the experimental point was located. The water in the tank was continuously oxygenated, and feeding was prohibited during the holding process. Other juvenile Prenant's schizothoracin were sent to the laboratory of Sichuan University. The fish were kept in 4 tanks (length: $0.6 \mathrm{~m}$; width: $0.6 \mathrm{~m}$; and water depth: $0.45 \mathrm{~m}$ ) for acclimatization. The fish were kept in freshwater for 2 days to eliminate the stress reaction in the transportation process. At that time, the oxygen saturation was increased by $100 \pm 2 \%$ with an oxygen pump, and the water was cleaned every 12 hours.

\section{Net-Cage Experiment}

We established an experimental platform in the downstream channel of Dagangshan Dam (Fig. 1 shows the experimental point). During flood discharge of the upstream dam, the experimental fish were placed in cages with different depths (0 1 $\mathrm{m}, 1 \sim 2 \mathrm{~m}, 2 \sim 3 \mathrm{~m}$, and $0 \sim 3 \mathrm{~m})$ that were fixed on the experimental platform. The experimental cages were checked every morning. To assess the survival of the fish, dead fish were removed from the various cages with nets. The weight and length of each dead experimental fish were measured on the experimental platform, symptoms of bubble disease on the body surface were observed, and typical symptoms were photographed. During the lethal flooding and supersaturation stress killing experiments, the TDG concentration

Table 1: Numbers, lengths and weights of the experimental fish.

\begin{tabular}{|lllll|}
\hline & & Sample size & Fork length $(\mathrm{cm})$ & Weight $(\mathrm{g})$ \\
\hline Field experiments & $0 \sim 1 \mathrm{~m}$ & 60 & $10.38 \pm 2.19$ & $10.63 \pm 4.82$ \\
& $1 \sim 2 \mathrm{~m}$ & 60 & $9.57 \pm 1.58$ & $8.92 \pm 3.63$ \\
& $2 \sim 3 \mathrm{~m}$ & 60 & $10.68 \pm 2.13$ & $9.98 \pm 4.37$ \\
& $0 \sim 3 \mathrm{~m}$ & 60 & $10.35 \pm 1.42$ & $9.71 \pm 4.03$ \\
Laboratory experiment & Lethal experiments & 40 & $9.41 \pm 1.32$ & $7.92 \pm 2.41$ \\
& Physiological experiment & 72 & $11.27 \pm 1.80$ & $12.30 \pm 3.4$ \\
\hline
\end{tabular}


at the experimental point was determined with a TGP meter (Point Four, Canada).

After flood discharge, the surviving experimental fish were removed from the cages and immediately transported approximately 120 kilometres to Heimao Extension Station of the Pubugou Hydropower Station. The experimental fish were grouped according to exposure death and kept in different water tanks; the group and death date of each dead fish were recorded. The water quality was tested once a month, and recovery from air bubble disease in the fish that were subjected to saturation stress was observed. During recovery in clean water, the water quality of each set of water tanks was monitored once a month. The TDG concentration was monitored using a Point Four TGP meter, and the DO concentration was monitored using an Oxyguard TGP meter (Oxyguard, Denmark).

\section{Lethality Experiment in the Laboratory}

The laboratory experiments were conducted at the State Key Laboratory of Hydraulics and Mountain River Development and Protection, Sichuan University. The experimental setup is shown in Fig. 2. TDG supersaturated water was produced by increasing the pressure of the water supply, and the required TDG saturation was achieved by adjusting the volume of freshwater. The volume of TDG supersaturated water was adjusted to the concentration level of $125 \%$. Oxygen supersaturation exposure was performed in a tank (width: $0.6 \mathrm{~m}$; depth: $0.45 \mathrm{~m}$ ) when the supersaturated concentration was completely stable. The experimental water depth was approximately $0.35 \mathrm{~m}$. The water tank was divided into two



Fig. 1: Location of the study sites on the mainstem of the Dadu River in Sichuan Province, China. parts with a plexiglass orifice plate, and each part was filled with 20 experimental fish. The behaviours of the fish were observed and recorded in the experiment, and the death time of each experimental fish was recorded. During the experiment, portable oxygen meters (Point Four trackers) were placed near the bottoms of the respective tanks, where TDG oversaturation was measured. The temperature was $11.4 \pm 0.3^{\circ} \mathrm{C}$, and the $\mathrm{pH}$ was $7.1 \pm 0.2$.

\section{Sample Treatment}

The experimental device for assessing the physiological responses of the juvenile fish to supersaturation was the same as the lethal experimental device. The first group was used to test the biochemical reactions of oversaturation stress within 6 hours, and the second group was used to test the biochemical reactions during the restoration in freshwater after six hours of exposure.

Six Prenant's schizothoracin were randomly selected every hour during the exposure period. After being anaesthetized with $0.3 \mathrm{mg} / \mathrm{L}$ of MC 222, blood was collected from the caudal arteries of the fish with a syringe. Each of the three was considered a sample. The sampling process in the recovery experiment was consistent with that in the exposure experiment. The blood samples were centrifuged for 20 minutes with a TGL-M high speed and low temperature centrifuge at $10000 \mathrm{r} / \mathrm{s}$. The serum biochemical indexes were detected with a Cobas c311 automatic biochemical analyser. During exposure to TDG supersaturation, six fish were taken at random each hour. Parallel samples were taken for each tissue sample. The gills and muscles were excised

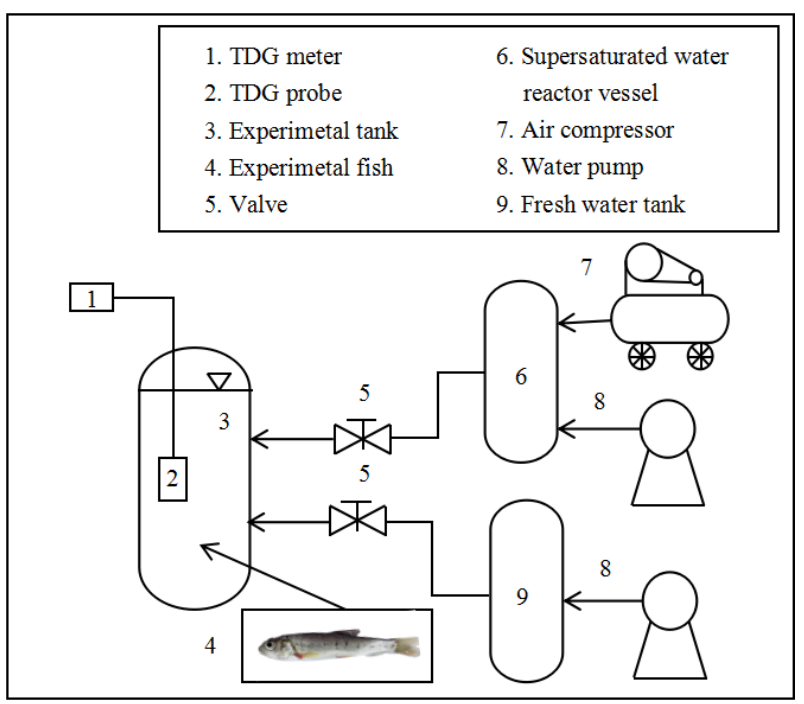

Fig. 2: Sketch of the experimental setup in the laboratory. 
and weighed. A total of $0.2 \mathrm{~g}$ of tissue was removed from the muscles and gills and placed into a $1 \mathrm{~mL}$ centrifuge tube for the detection of superoxide dismutase (SOD) and CAT. A total of $0.3 \mathrm{~g}$ of muscle was placed into a $1 \mathrm{~mL}$ centrifuge tube to measure the MDA content.

\section{Biochemical Assays}

Then, $1.6 \mathrm{~mL}$ of $0.05 \mathrm{~mol} / \mathrm{L}$ sodium phosphate buffer $(\mathrm{pH}$ 7.8) was added to the centrifuge tube containing $0.2 \mathrm{~g}$ of the tissue sample, soaked in liquid nitrogen and ground in a multi-sample tissue grinder. Then, the crude extract was obtained at $12000 \mathrm{r} / \mathrm{min}$ for 20 minutes at $4^{\circ} \mathrm{C}$. The supernatant was obtained and used for assaying the SOD and CAT enzyme activities. Based on the experimental scheme of (Liu et al. 2011), the SOD and CAT assay was carried out.

The samples were prepared and tested within 24 hours. The sampling and preparation methods of enzymatic activity in the recovery process were consistent with the exposure process.

\section{Statistical Analysis}

The data were presented as the mean \pm standard deviation (SD). For the physiological indicators, the difference between groups was determined by one-way analysis of variance (ANOVA), and Duncan's test was applied. The two groups were considered to be statistically different at $\mathrm{P}<0.05$. The computer programme SPSS for Win 8.0 was used. This paper uses original display pictures.

\section{RESULTS}

\section{Net-Cage Experiment}

The flood discharge lasted approximately 5 days. The flood discharge began at 9:00 every morning and lasted until 5 pm. During the period, the water in the river was always saturated, and the values of TDG and DO fluctuated little. The maximum TDG was $117.6 \%$, the minimum was $105.8 \%$, and the average was $110.5 \%$; the maximum DO was 10.21 $\mathrm{mg} / \mathrm{L}$, the minimum was $7.65 \mathrm{mg} / \mathrm{L}$, and the average was $9.20 \mathrm{mg} / \mathrm{L}$ [Fig. 3(a)]. In the cages with different depths, the number of dead fish in the surface water $(0 \sim 1 \mathrm{~m})$ was significantly higher than those in the other cages [Fig. 3(b1)]. Some obvious symptoms of bubble disease were found on the dead experimental fish. The experimental fish in each cage showed differences in their death characteristics and symptoms and the probability of bubble disease were shown in [Fig. 3 (c)]. The experimental fish suffering from air bubble disease after the end of flood discharge was placed in clear water and observed. After approximately 180 days, all the experimental fish died, and there were no significant differences in the death characteristics of the different groups.

\section{Lethality Experiment in the Laboratory}

The water depth of the laboratory water tank was approximately $0.35 \mathrm{~m}$, and the TDG fluctuated in the range of $118.0 \sim 131.0 \%$, with an average of $127.8 \%$. The average value of DO in the $117.9 \sim 129.0 \%$ range was $123.4 \%$ [Fig. 4(a)]. The juvenile larvae had more obvious death characteristics in the supersaturated water, and no death occurred in the first stage. The experimental fish began to die after approximately 6.7 hours. The second stage was the start of death to the semi-lethal time (12 hours), and death occurs faster. The third stage was from the semi-lethal time to total death (31.5 hours), and death was slower Fig. 4(b).

\section{Biochemical Responses}

Under supersaturation stress, the enzymes in the blood of (a)

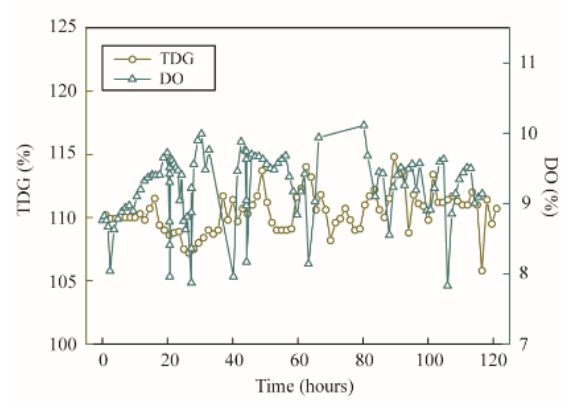

(b)

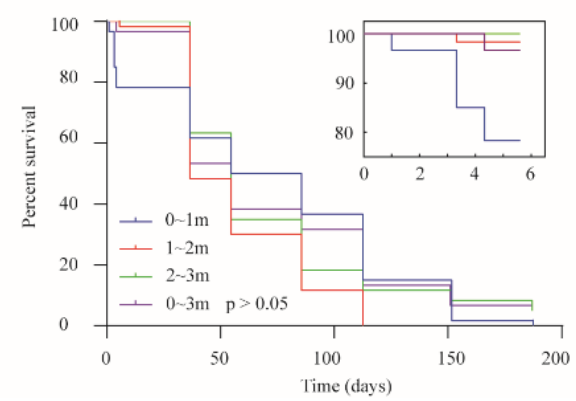

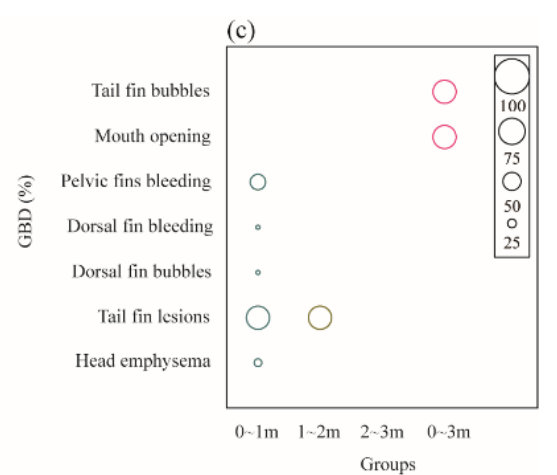

Fig. 3: During flood discharge, the performances of the experimental fish that were subjected to supersaturation stress were assessed. (a) TDG changes in the flood discharge processes; (b) survival curve of the experimental fish with bubble disease at varying water depth and survival curve of the control group (the small image is part of the survival curve of the flood discharge process); (c) probability of bubble disease in the experimental fish at different water depths during the flood discharge. 
(a)

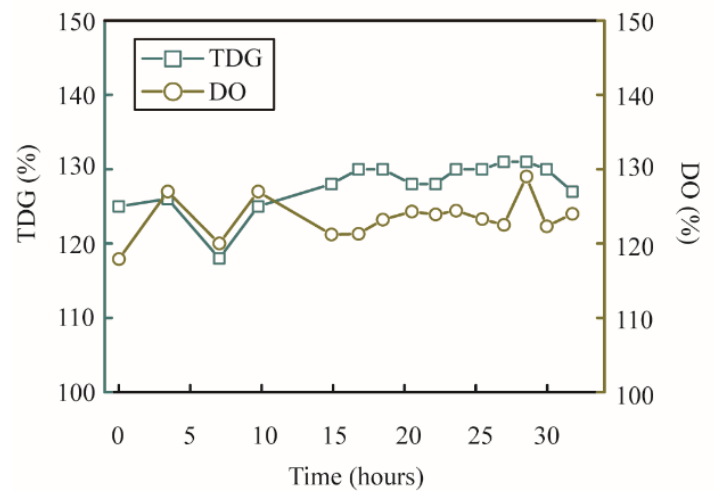

(b)

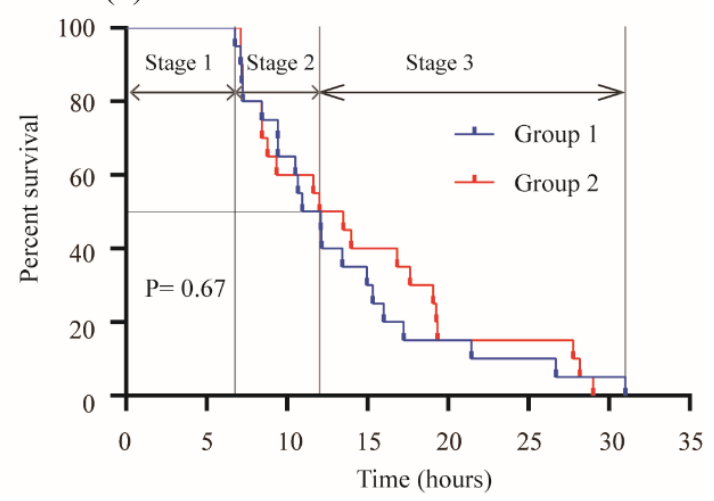

Fig. 4: The performances of the experimental fish that were subjected to supersaturation stress were assessed in laboratory. (a) TDG changes during the processes; (b) survival curve of the experimental fish with bubble disease.

the experimental fish showed obvious changes. Aspartate aminotransferase activity increased first and then began to decline a small amount. At the third hour, the activity level decreased to a value that was close to the control value, which was 1.2 times that of the control group. The regularity of creatine kinase activity was consistent with the trend in aspartate aminotransferase, i.e. increasing first, and after the first hour, continuing to increase from 2 to 6 hours, and the value was 2.3 times that of the exposed group at 6 hours [Fig. 5( $\left.a_{1}\right)$ ]. The amount of A enzyme in the blood decreased from 1.9 times to 1.3 times in the control group. There was an upward trend between 3 and 5 hours. The maximum value at 5 hours was 2.4 times that of the control group and 2.1 times that of the control group by the 6th hour of recovery. The variation trend in the $\mathrm{C}$ enzyme was consistent with that of the A enzyme. From 0 3 hours, a downward trend was observed, from 2.3 times that of the control group to 1.35 times that of the control group. From 3-5 hours, an upward trend was observed, with the highest value at 5 hours being 3.2 times that of the control group and 2 times that of the control group at 6 hours [Fig. $\left.5\left(\mathrm{a}_{2}\right)\right]$.

When the experimental fish were exposed to $125 \%$ supersaturated water, the supersaturated environment activated the antioxidant system of the fish. The activities of SOD, CAT, and MDA changed significantly within 6 hours.

The MDA value declined first and then increased within 6 hours, and the changed trend was consistent with that of SOD. After the first 2 hours, the MDA value decreased significantly, remained at a low value until the fourth hour, and increased at the fifth hour. There was no increase at the 6th hour and the value was 0.87 times that of the control group. The experimental fish that were exposed to $125 \%$ supersaturated water did not die [Fig. 5( $\left.b_{1}\right)$ ]. The supersaturation valve was closed, and the saturation level was reduced to $100 \%$ at the same temperature and water level of the water tank. The enzyme indices were tested for 6 hours to observe the law of self-recovery of the antioxidant system of the experimental fish. The MDA values showed an upward trend between 4 and 6 hours of exposure but continued to decline within 6 hours of recovery, from 0.86 times that of the control group to 0.39 times [Fig. $5\left(b_{2}\right)$ ]. The CAT value began to increase rapidly during the first hour and reached a maximum value of 8.4 times that of the unexposed group. When the high value was maintained at the second hour, the value slowly decreased from the second hour to the sixth hour, and there was no significant difference between the CAT value and the control group value [Fig. $5\left(b_{3}\right)$ ]. CAT activity decreased significantly during the exposure period from 2 to 6 hours and increased significantly during the recovery period from 0 to 3 hours, from 0.73 times to 1.6 times that of the control group; the value remained relatively high from 3 to 6 hours, at 1.58 times the value of the control group at 6 hours [Fig. $\left.5\left(b_{4}\right)\right]$. SOD activity showed a trend of first decreasing and then increasing. SOD activity decreased significantly in the first two hours and remained at a low level from the second hour to the fifth hour. SOD activity was significantly inhibited by oversaturation [Fig. $\left.5\left(b_{5}\right)\right]$. For enzyme activity in the muscles, the value of SOD increased at 5-6 hours of exposure but decreased slowly from 0-6 hours during recovery, from 0.89 times to 0.7 times that of the control group [Fig. $5\left(b_{6}\right)$ ].

The changes in SOD and CAT in the gills under highly saturated stress were significant, but the supersaturation change trends observed in the fish differed. CAT continued to increase after the first hour, and at 6 hours, the value was 6.8 times that of the control group, which was significantly higher than the value without exposure. The relative enzyme activity in the fish gills was higher than that in the muscles, indicating that the enzymes in the fish gills were more sensi- 
(a)

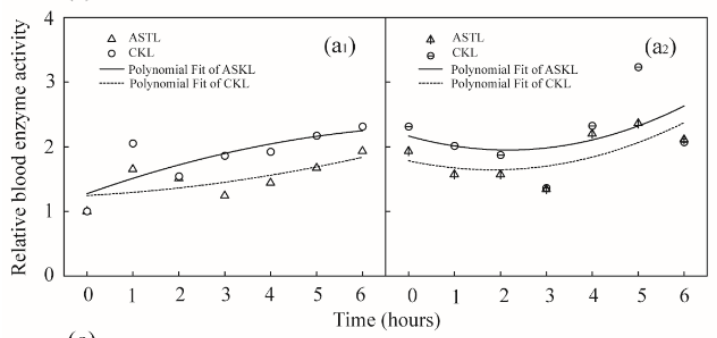

(c)

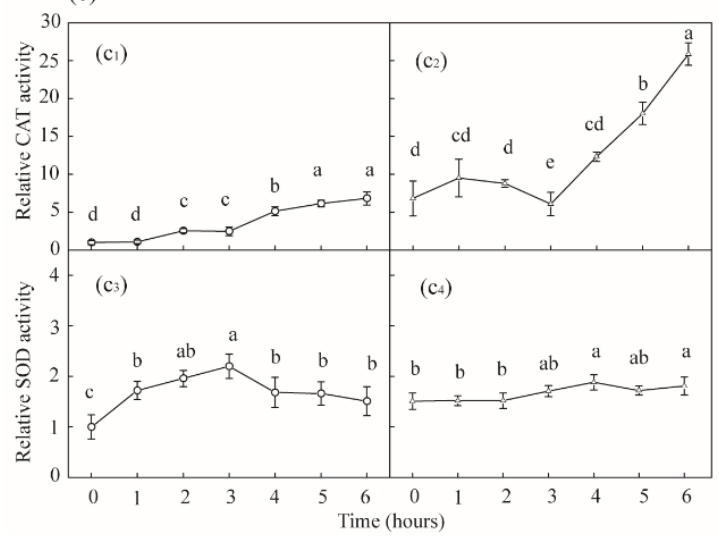

(b)

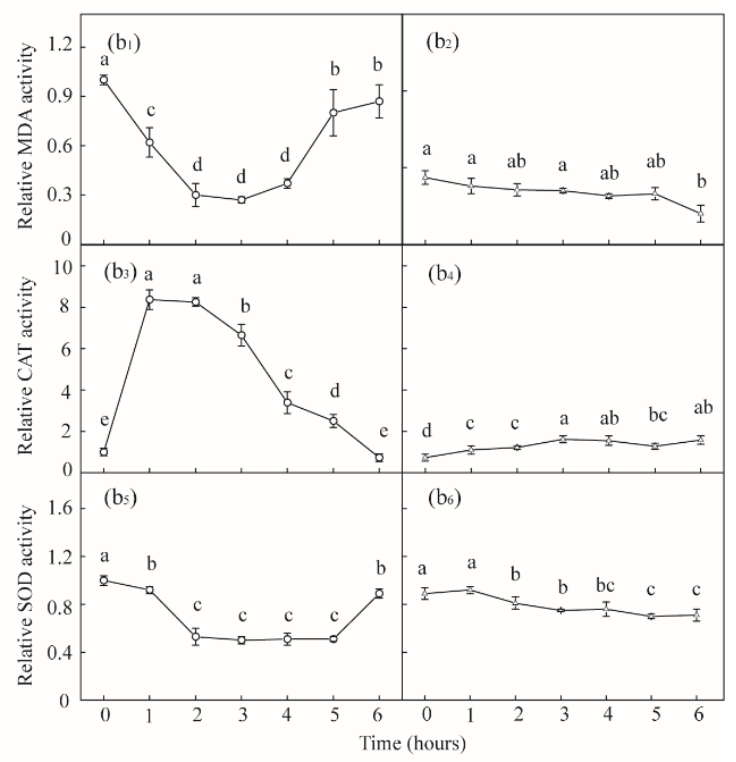

Fig. 5 (a) Changes in enzymatic activity in the blood of Prenant's schizothoracin $\left[\left(\mathrm{a}_{1}\right)\right.$ aspartate aminotransferase and creatine kinase activities after exposure to TDG, and $\left(\mathrm{a}_{2}\right)$ aspartate aminotransferase and creatine kinase activities in freshwater]; (b) changes in enzymatic activity in the muscle of Prenant's schizothoracin $\left[\left(b_{1}\right)\right.$ relative MDA activity after exposure to TDG, $\left(b_{2}\right)$ relative MDA activity in freshwater, $\left(b_{3}\right)$ relative CAT activity after exposure to TDG, $\left(b_{4}\right)$ relative CAT activity in freshwater, $\left(b_{5}\right)$ relative SOD activity after exposure to TDG, and $\left(b_{6}\right)$ relative SOD activity in fresh water]; (c) changes in enzymatic activity in the gills of Prenant's schizothoracin $\left[\left(\mathrm{c}_{1}\right)\right.$ relative CAT activity after exposure to TDG, $\left(\mathrm{c}_{2}\right)$ relative CAT activity in freshwater, $\left(\mathrm{c}_{3}\right)$ relative SOD activity after exposure to TDG, and $\left(\mathrm{c}_{4}\right)$ relative SOD activity in freshwater].

tive to the stress of oversaturation [Fig. 5( $\left.\left.\mathrm{c}_{1}\right)\right]$. CAT increased continuously during the exposure period, and the value was 6.8 times that of the relative control group at 6 hours; the value continued to increase during the recovery period, and the value was 25.8 times that of the relative control group at the recovery time of 6 hours [Fig. $\left.5\left(c_{2}\right)\right]$. SOD rose sharply in the first three hours, with a maximum exposure of 3 hours at 2.2 times the control value, and then began to decline after 4 hours. There was no significant change from 4 to 6 hours, and the value was approximately 1.6 times that of the control group [Fig. 5( $\left.\mathrm{c}_{3}\right)$ ]. For SOD, after fish were exposed to supersaturation for 3 6 hours, a downward trend was observed; the level continued to increase during recovery, and the value increased from 1.5 times to 1.8 times that of the relative control group [Fig. $\left.5\left(\mathrm{c}_{4}\right)\right]$.

\section{DISCUSSION}

\section{Net-Cage Experiment}

The concentration of supersaturated water in the river at our field site during this experiment averaged $110 \%$, and juvenile Prenant's schizothoracin with bubble disease were found in the cages (Fig. 3). The symptoms observed were similar to those observed in previous field studies of fish in supersaturated water (Renfro 1963). Another obvious phenomenon was that the death rate of young fish in the $0 \sim 1 \mathrm{~m}$ surface cage was highest in the saturated water under stress. Juvenile Chinook salmon and steelhead in the Columbia and Snake River Basins were existing at a water depth with TDG oversaturation most of the time, between 2 and $4 \mathrm{~m}$, and the level was rarely above 2 m (Beeman \& Maule 2006, Johnson et al. 2005). The avoidance ability of Chinese suckers in the vertical direction was observed when the fish were exposed to water with high TDG levels. The fish in clear water remained at a depth of 2 3 $\mathrm{m}$ and kept diving below $4 \mathrm{~m}$ when the oversaturated water concentration was $150 \%$ (Cao et al. 2016).

Fish caught in supersaturated river water had different stress levels and different symptoms of bubble disease (Weitkamp et al. 2003). Bubble disease is also more difficult to detect in young fish than in adults (Smiley et al. 2011). However, in addition to bubble disease symptoms that can be observed with the naked eye, supersaturation stress can also cause internal damage (Bouck 1980, Newcomb 1974). 
Just because bubble disease is observed to be mild, it does not mean that the damage to the fish was minor. Symptoms of GBT could be observed in sockeye salmon and steelhead when the TDG concentration level exceeded $126 \%$, while symptoms of bubble disease in Chinook salmon were still rarely observed when the TDG level exceeded 130\% (Backman \& Evans 2002). At the end of the field experiment, the surviving fish were placed in clear water and observed. No obvious symptoms of bubble disease were observed in the surviving juvenile fish, but they continued to die in the clear water. This result indicates that irreversible damage was caused by low supersaturation concentrations and longterm stress. In addition, the death rate of fish at different water depths showed no significant difference. For juvenile schizostoma, compensating for the water depth in the channel could not significantly alleviate the negative harm of supersaturation to the experimental fish.

\section{Acute Lethal Experiments}

At the start of the experiment, fish swam freely around the tank. Abnormal behaviour began to be observed approximately 7 hours later, and the fish began to gather at the bottom and corners of the tanks. Some fish were very active, and some fish started to swim quickly and suddenly; side swimming was observed. Bubble disease began to unbalance the fish, and they sometimes jumped in the air and then fell slowly to the bottom of the tank. At approximately hour 12, the fish began to die. Dead experimental fish floated on the water, and their mouths were wide open. Bubble disease could be observed on some of the dead experimental fish, such as bubbles on fins, the protrusion of eyes and protrusions of the abdomen. In oversaturated water, the behaviours of white bass include loss of buoyancy control, lethargy, crashing into the walls and bottoms of aquariums, occasional darting, violent shaking, the rapid opening of the mouth, opening of the gills, and swimming at the bottom of the tank (Smiley et al. 2011). Chinese suckers show signs of spinning, and in some cases, they float to the surface of the water and go back to the bottom, where they lie (Cao et al. 2016). Fish held in supersaturated water show an increase in swim bladder pressure, and gas is expelled through the pneumatic duct, which may explain the abnormal behaviour of the experimental fish when exposed to supersaturation to some extent (Shrimpton et al. 1990).

The processes of fish exposure to supersaturated water, suffering from bubble disease and eventually dying could be divided into three distinct periods. We found that there were three stages of supersaturated death of the juvenile fish under laboratory conditions, which is consistent with previous studies. During the first phase, bubbles begin to form in the blood vessels. The second stage is the time when the mortality rate is gradually increasing. The third stage of death is slow and lasts relatively longer (Bouck 1980).

The tolerances of different fish to TDG oversaturated water often differ. The lethal exposure times to $50 \%$ mortality for Chinook and steelhead at $125 \%$ nitrogen saturation were 13.6 hours and 14.2 hours, respectively. The median lethal time $\left(\mathrm{LT}_{50}\right)$ was determined to evaluate the acute lethal effects on several species of endemic fish to the upper reaches of the Yangtze River at a level of $125 \%$ supersaturation. The shortest time was observed for juvenile rock carp, 15.4 hours (Huang et al. 2010), followed by Chinese suckers (Myxocyprinus asiaticus Bleeker), with an $\mathrm{LC}_{50}$ value of $43.4 \mathrm{~h}$ (Chen et al. 2012). Silver carp tolerated supersaturation best, with a lethal time of approximately $67.71 \mathrm{~h}$ (Cao et al. 2016). Compared with the half-lethal times of several species that are endemic to the middle and upper reaches of the Yangtze River under the same laboratory conditions, the half-lethal time of juvenile Schizothorax chinensis was 12 hours, which showed poor tolerance to supersaturation.

\section{Biochemical Indicator of Blood Serum}

Fish may experience physiological and blood composition changes in response to the level of oxygen in the water. Under the condition of water hypoxia, the blood pressure in the abdominal aorta and dorsal aorta of fish slightly decreases, and the amount of haemoglobin also decreases (Holeton 1972). The serum potassium, phosphate and serum albumin, calcium, cholesterol, total protein and alkaline phosphatase levels in steelhead increased after 35 days of exposure to $110 \%$ total atmospheric gas saturation (Newcomb 1974). Long-term supersaturation stress changes the blood gas exchange, $\mathrm{pH}$, plasma ion, respiratory rate and cardiovascular function of fish (Wilkes et al. 1981). In freshwater rainbow trout, respiratory acidosis that was induced by $70 \mathrm{~h}$ of exposure to a high oxygen environment was also associated with the reduction in the gill chlorine cell surface area (CCFA). After 72 hours of exposure to high oxygen levels, metabolic alkalosis was observed in normal water for 6 hours (Gilmour \& Perry 1994). The content of AST is low in fish with normal physiological states. When the body is under stress, AST is released into the blood from liver cells. AST is also often used as the detection index of environmental stress, especially toxicity tests. We found liver cell damage in the juvenile fish that experienced supersaturated water stress. The increasing concentration in the $\mathrm{CK}$ was consistent with the observed abnormal activity [Fig. 5 (a)].

Blood markers can also describe a fish's recovery from bubble disease. In Clarias batrachus and Heteropneustes fossilis with severe bubble disease, bubble collapse led 
to liver, kidney, tubule and glomerular degeneration and haematopoietic necrosis. At the same time, the erythrocyte count and haemoglobin content decreased significantly. After a period of recovery, normal swimming was restored, and the red blood cell counts and haemoglobin levels also recovered from the disease (Kulshrestha \& Mandal 1982). In hyper-aerobic processes, the ultimate recovery of both $\mathrm{pHe}$ and pHi must occur in the kidneys or gills (Wood et al. 1984). However, in our observations, the blood indicators showed no signs of recovery after 6 hours of stress [Fig. 5 (b)].

\section{Activities of Antioxidant Enzymes}

The enzyme activities in the gills of fish tend to be more sensitive than those in the muscles (Fig. 5). Liu indicated that CAT activities in gills were higher than those in muscles (Liu et al. 2011). Severe damage to fish gills caused by high oxygen and high pressure in supersaturated water is a major cause of death (Barthelemy et al. 1981, Sebert et al. 1984). One possible reason is that hyperoxia induces respiratory acidosis in rainbow trout, and $90 \%$ of the net acid is excreted through fish gills (Wood 1991).

Previous studies have shown that antioxidant enzyme activity can be used to evaluate the degree of stress of TDG oversaturated water on fish. Chen found that changes in the CAT activities in the muscles and gills of Chinese suckers that were exposed to a gas saturation level of $140 \%$ exhibited a regular decrease after an increase. The CAT activities in the muscles could return to the normal level at $\mathrm{LT}_{50}$. However, the CAT activities in the gills were significantly lower than those in the control group (TDG level of 100\%) after 3/5 $\mathrm{LT}_{50}$ (Chen et al. 2012). Qing Liu demonstrated that CAT activity in the muscles and gills of juvenile rock carp increased after long-term exposure at low TDG levels. CAT activity in the muscles increased 1.7 -fold at $112 \%$, and the activity in gills that were exposed to a $108 \%$ level of TDG was 1.5-fold higher than that in the control group at 21 days (Qing Liu et al. 2015). Asian carp were exposed to a $140 \%$ concentration of supersaturated water. The CAT activity increased significantly within 2 hours. Over time, the CAT activity gradually decreased, and the CAT activity in the oversaturated fish was lower than that in the fish in fresh water at 5 hours (Cao et al. 2016). The variation trend in SOD activity in oversaturated fish was consistent with that in CAT activity (Qing Liu et al. 2015). The content of MDA can be used as an index to investigate the severity of cell stress. Research on variation trends in MDA is lacking.

In our study, the variation trend in enzyme activity over time in Prenant's schizothoracin under saturated stress showed that CAT activity first increased and then decreased over time, which was consistent with previous studies (Cao et al. 2016, Chen et al. 2012). SOD and MDA decreased first and then increased over time. The SOD activity results were inconsistent with the findings of previous studies (Liu et al. 2011, Qing Liu et al. 2015), mainly because those studies assessed long-term changes in fish exposure, while our study assessed short time changes. The activities of the three enzymes in our study, SOD, CAT and MDA, in the muscles of the fish showed relatively obvious recovery phenomena within 6 hours, indicating that the fish had a certain adaptability and self-regulation ability in response to supersaturation stress within the recovery time range.

Previous studies found that fish suffering from bubble disease in oversaturated water can recover to some extent (Knittel et al. 1980, Meekin \& Turner 1974). Signs of recovery were observed in fizzy trout (Rukavina \& Varenika 1956). After being exposed to oversaturated water for 96 hours, fish recovery was observed. There was no significant difference between the red blood cells and haemoglobin, and the swimming performance returned to normal (Kulshrestha $\&$ Mandal 1982). Some species of fish are highly adapted to supersaturated environments. Sea bass can recover quickly when exposed to normal conditions after being exposed to a TDG level greater than 220\% (Lemarié et al. 2011).

\section{CONCLUSION}

In this study, the physiological and biochemical reactions of Prenant's schizothoracin were determined during recovery in water after exposure to a supersaturation concentration of $125 \%$ after 6 hours of stress. The results showed that the SOD enzyme activity and MDA activity in the muscles of fish continued to decline within 6 hours, and the CAT activity in the muscles and SOD activity and CAT activity in the gills of fish continued to decline. These findings indicate that the antioxidant enzyme activity of fish cannot effectively recover in clear water after 6 hours. The changes in AST enzyme activity and CK enzyme activity in the fish serums were consistent, and the recovery trend was obvious within 6 hours.

\section{ACKNOWLEDGMENTS}

This work was supported by the National Natural Science Foundation of China (Grants 51379136 and 51509213) and the National Key Project for Research and Development Plan (2016YFC0401710).

\section{REFERENCES}

Backman, T.W. and Evans, A.F. 2002. Gas bubble trauma incidence in adult salmonids in the Columbia River Basin. North American Journal of Fisheries Management, 22: 579-584. 
Bálint, T., Ferenczy, J., Kátai, F., Kiss, I., Kráczer, L., Kufcsák, O., Láng, G., Polyhos, C., Szabó, I. and Szegletes, T. 1997. Similarities and differences between the massive eel (Anguilla anguilla L.) devastations that occurred in Lake Balaton in 1991 and 1995. Ecotoxicology and Environmental Safety, 37: 17-23.

Barthelemy, L., Belaud, A. and Chastel, C. 1981. A comparative study of oxygen toxicity in vertebrates. Respiration Physiology, 44: 261-268.

Beeman, J.W. and Maule, A.G. 2006. Migration depths of juvenile Chinook salmon and steelhead relative to total dissolved gas supersaturation in a Columbia River reservoir. Transactions of the American Fisheries Society, 135: 584-594.

Bouck, G.R. 1980. Etiology of gas bubble disease. Transactions of the American Fisheries Society, 109: 703-707.

Cao, L., Li, K., Liang, R., Chen, S., Jiang, W. and Li, R. 2016. The tolerance threshold of Chinese sucker to total dissolved gas supersaturation. Aquaculture Research, 47: 2804-2813.

Cao, L., Liang, R., Tuo, Y., Li, Y. and Li, K. 2016. Influence of total dissolved gas-supersaturated water on silver carp (Hypophthalmichthys molitrix). Water Science and Engineering, 9: 324-328.

Ceron, J. J., Sancho, E., Ferrando, M.D., Gutierrez, C. and Andreu, E. 1996. Metabolic effects of diazinon on the European eel: Anguilla anguilla. Journal of Environmental Science and Health Part B, 31: 1029-1040.

Chen, S., Liu, X., Jiang, W., Li, K., Du, J., Shen, D. and Gong, Q. 2012. Effects of total dissolved gas supersaturated water on lethality and catalase activity of Chinese sucker (Myxocyprinus asiaticus Bleeker). Journal of Zhejiang University Science B, 13: 791-796.

Colt, J.E., Orwicz, K. and Brooks, D. 1991. Gas supersaturation in the American River. California Fish and Game, 77: 41-50.

Ebel, W.J. and Raymond, H.L. 1976. Effect of atmospheric gas supersaturation on salmon and steelhead trout of the Snake and Columbia rivers. Marine Fisheries Review, 38: 1-14.

Gilmour, K. and Perry, S. 1994. The effects of hypoxia, hyperoxia or hypercapnia on the acid-base disequilibrium in the arterial blood of rainbow trout. Journal of Experimental Biology, 192: 269-284.

Gray, R.H., Page, T.L. and Saroglia, M.G. 1983. Behavioral response of carp, Cyprinus carpio, and black bullhead, Ictalurus melas, from Italy to gas supersaturated water. Environmental Biology of Fishes, 8: 163-167.

Holeton, G.F. 1972. Gas exchange in fish with and without hemoglobin. Respiration Physiology, 14: 142-150.

Huang, X., Li, K., Du, J. and Li, R. 2010. Effects of gas supersaturation on lethality and avoidance responses in juvenile rock carp (Procypris rabaudi Tchang). Journal of Zhejiang University Science B, 11: 806-811.

Jensen, J. 1988. Combined effects of gas supersaturation and dissolved oxygen levels on steelhead trout (Salmo gairdneri) eggs, larvae, and fry. Aquaculture, 68: 131-139.

Johnson, E.L., Clabough, T.S., Bennett, D.H., Bjornn, T.C., Peery, C.A., Caudill, C.C. and Stuehrenberg, L.C. 2005. Migration depths of adult spring and summer Chinook salmon in the lower Columbia and Snake rivers in relation to dissolved gas supersaturation. Transactions of the American Fisheries Society, 134: 1213-1227.

Knittel, M.D., Chapman, G.A. and Garton, R.R. 1980. Effects of hydrostatic pressure on steelhead survival in air-supersaturated water. Transactions of the American Fisheries Society, 109: 755-759.

Krise, W.F. 1993. Effects of one-year exposures to gas supersaturation on lake trout. The Progressive Fish Culturist, 55: 169-176.

Krise, W.F. and Herman, R.L. 1989. Tolerance of lake trout, Salvelinus namaycush (Walbaum), sac fry to dissolved gas supersaturation. Journal of Fish Diseases, 12: 269-273.

Kulshrestha, A.K. and Mandal, P.K. 1982. Pathology of gas bubble disease in two air-breathing catfishes (Clarias batrachus Linn. and Heteropneustes fossilis Bloch.). Aquaculture, 27: 13-17.
Lemarié, G., Hosfeld, C.D., Breuil, G. and Fivelstad, S. 2011. Effects of hyperoxic water conditions under different total gas pressures in European sea bass (Dicentrarchus labrax). Aquaculture, 318: 191-198.

Liu, X., Li, K., Du, J., Li, J. and Li, R. 2011. Growth rate, catalase and superoxide dismutase activities in rock carp (Procypris rabaudi Tchang) exposed to supersaturated total dissolved gas. Journal of Zhejiang University Science B, 12: 909.

Livingstone, D.R. 2001. Contaminant-stimulated reactive oxygen species production and oxidative damage in aquatic organisms. Marine Pollution Bulletin, 42: 656-666.

Meekin, T.K. and Turner, B.K. 1974. Tolerance of salmonid eggs, juveniles and squawfish to supersaturated nitrogen. Nitrogen Supersaturation Investigations in the Mid-Columbia River, Washington Department of Fisheries Technical Report, p. 75-126.

Mesa, M.G., Weiland, L.K. and Maule, A.G. 2000. Progression and severity of gas bubble trauma in juvenile salmonids. Transactions of the American Fisheries Society, 129: 174-185.

Mesa, M.G. and Warren, J.J. 1997. Predator avoidance ability of juvenile chinook salmon (Oncorhynchus tshawytscha) subjected to sublethal exposures of gas-supersaturated water. Canadian Journal of Fisheries and Aquatic Sciences, 54: 757-764.

Nakasone, H. 1987. Study of aeration at weirs and cascades. Journal of Environmental Engineering, 113: 64-81.

Newcomb, T.W. 1974. Changes in blood chemistry of juvenile steelhead trout, Salmo gairdneri, following sublethal exposure to nitrogen supersaturation. Journal of the Fisheries Board of Canada, 31: 19531957.

Qing Liu, X., K. Feng Li, Jiang, W. and Wu, S. 2015. Biochemical responses and survival of rock carp (Procypris rabaudi) to total dissolved gas supersaturated water. Ichthyological Research, 62: 171-176.

Qu, L., Li, R., Li, J., Li, K. and Deng, Y. 2011. Field observation of total dissolved gas supersaturation of high-dams. Science China Technological Sciences, 54: 156-162.

Renfro, W.C. 1963. Gas-bubble mortality of fishes in Galveston Bay, Texas. Transactions of the American Fisheries Society, 92: 320-322.

Rukavina, J. and Varenika, D. 1956. Air bubble disease of trout at the source of the river Bosna. Sport Fishery Abstr., 4147.

Ryan, B.A. and Dawley, E.M. 1998. Effects of dissolved gas supersaturation on fish residing in the Snake and Columbia rivers, 1997, Bonneville Power Administration.

Sebert, P., Barthelemy, L. and Peyraud, C. 1984. Oxygen toxicity in trout at two seasons. Comparative Biochemistry and Physiology Part A: Physiology, 78: 719-722.

Shrimpton, J.M., Randall, D.J. and Fidler, L.E. 1990. Factors affecting swim bladder volume in rainbow trout (Oncorhynchus mykiss) held in gas supersaturated water. Canadian Journal of Zoology, 68: 962-968.

Smiley, J.E., Drawbridge, M.A., Okihiro, M.S. and Kaufmann, R.S. 2011. Acute effects of gas supersaturation on juvenile cultured White Seabass. Transactions of the American Fisheries Society, 140: 1269-1276.

Stevens, D.G., Nebeker, A.V. and Baker, R.J. 1980. Avoidance responses of salmon and trout to air-supersaturated water. Transactions of the American Fisheries Society, 109: 751-754.

Weitkamp, D.E., Sullivan, R.D., Swant, T. and DosSantos, J. 2003. Gas bubble disease in resident fish of the lower Clark Fork River. Transactions of the American Fisheries Society, 132: 865-876.

Weitkamp, D.E. and Katz, M. 1980. A review of dissolved gas supersaturation literature. Transactions of the American Fisheries Society, 109: 659-702.

Wilkes, P., Walker, R.L., McDonald, D.G. and Wood, C.M. 1981. Respiratory, ventilatory, acid-base and ionoregulatory physiology of the white sucker Catostomus commersoni: The influence of hyperoxia. 
Journal of Experimental Biology, 91: 239-254.

Wood, C.M. 1991. Branchial ion and acid-base transfer in freshwater teleost fish: Environmental hyperoxia as a probe. Physiological Zoology, 64: 68-102.

Wood, C.M., Wheatly, M.G. and H be, H. 1984. The mechanisms of acid-base and ion regulation in the freshwater rainbow trout during environmental hyperoxia and subsequent normoxia. III. Branchial exchanges. Respiration physiology, 55: 175-192.

Yuan, Y., Wang, Y., Zhou, C., An, R. and Li, K. 2018. Tolerance of Prenant's schizothoracin Schizothorax prenanti to total dissolved gas supersaturated water at varying temperature. North American Journal of Aquaculture, 80: 107-115. 